\title{
Diferentes concepções de infância na literatura
}

\author{
Lígia Regina Máximo Cavalari Menna ${ }^{1}$
}

RESUMO: Neste artigo, pretendemos apresentar algumas concepções de infância representadas na literatura. Ao levarmos em conta que a infância é uma construção social, teremos diferentes concepções em diferentes épocas e lugares, sendo a literatura, destinada tanto ao público infantil como ao adulto, um espaço privilegiado para essa representação. Este artigo resulta de nossa pesquisa de doutorado, cujo tema é a Literatura Infantil fora do livro.

ABSTRACT: In this article, we intend to present some of childhood conceptions represented in literature. By taking into account that childhood is a social construction, there will be different conceptions in different times and places and, aimed at children as well as at adults, literature is a privileged space for representation. This article is a result of our doctorate research, whose theme is Children's Literature beyond the book.

PALAVRAS-CHAVE: Concepções de infância; Literatura; Literatura infantil KEY WORDS: Conception of childhood; Literature; Children's literature

Ao se propor um estudo sobre literatura infantil, é imprescindivel que se pense em seu público leitor por excelência, a criança e, por continuidade, a infância.

As concepções sobre a infância são as mais variadas possiveis. Assim, não se pretende esgotar o assunto, mesmo porque as polêmicas são diversas. Espera-se, portanto, apontar algumas considerações que elucidem melhor a infância e a criança, esse leitor privilegiado da literatura infantil.

\footnotetext{
${ }^{1}$ Doutoranda na Área de Estudos Comparados de Literaturas em Língua Portuguesa da FFLCH-USP, sob orientação do Prof. Dr. José Nicolau Gregorin Filho. Projeto: "Literatura Infantil fora do livro". Contato: ligiamenna@usp.br
} 
Vejamos, inicialmente, algumas acepções sobre o termo infância encontradas no dicionário Houaiss:

1- na vida do ser humano, período que vai do seu nascimento ao início da adolescência; meninice, puerícia 2- Rubrica: termo jurídico. periodo da vida que é legalmente definido como aquele que vai desde o nascimento até os 12 anos, quando se inicia a adolescência 3- o conjunto das crianças Ex.: muito se diz e se escreve, e pouco se faz pela educação da infância. 2

À primeira vista, parece simples entender o que é a infância. Mas, seria mesmo? Sempre foram essas as acepções? Em outras épocas, ela duraria, por exemplo, até os 12 anos, conforme a definição expressa nesse verbete?

Vejamos o que alguns estudiosos dizem a respeito.

Segundo Philippe Ariès, em História social da criança e família (1981), o termo "infância” nem sempre teve a acepção da atualidade. Para ele, o mundo medieval ignorava a infância, "não percebia o período transitório entre a infância e a idade adulta." Somente a partir do século XVII, houve uma evolução, um novo hábito da burguesia, agindo em maior acordo com a acepção mais moderna do termo.

Havia antes uma indiferença quanto aos fatores biológicos, pois a ideia de infância estava mais ligada à de dependência, um "petit garçon", por exemplo, não era necessariamente uma criança, poderia ser um serviçal.

Já para o inglês Colin Heywood, em seu livro Uma história da infância (2002), a infância só pode ser compreendida como uma construção social, ou seja, os termos "criança" e "infância" são compreendidos de formas diferentes, em diferentes épocas e lugares, estando condicionados a questões culturais, filosóficas, econômicas e por muitas vezes religiosas.

\footnotetext{
2 Dicionário Houaiss de Língua Portuguesa. Versão online, verbete “ infância” Acessado em 14/04/2010. http://houaiss.uol.com.br/busca.jhtm/verbete=infância
} 
A partir de uma perspectiva social e histórica, o autor conclui que não existe somente uma infância, mas várias.

Ele faz diferentes questionamentos: Crianças são inocentes ou manchadas pelo pecado original? A infância deveria ser longa ou curta? As crianças deveriam ser protegidas pelas famílias ou lançadas no mundo adulto? $O$ principal foco estaria na idade ou no gênero (masculino e feminino)?

Em seu livro, inclusive, opta por uma análise mais temática, e não cronológica, por considerar que temas e concepções se repetem em épocas diferentes, enquanto concepções opostas podem conviver em um mesmo período, ou seja, as respostas a essas perguntas podem ser bem variadas.

Em nossas pesquisas, verificamos, por exemplo, que em certas épocas, a infância se estendia até os sete anos, em outras, até os catorze.

Vale à pena ressaltar que Heywood critica Ariès em diferentes pontos, principalmente quando este diz que a infância era desconhecida na Idade Média. Entre os vários argumentos, ele cita outro estudioso, Anthony Burton, o qual afirma que a concentração em temas religiosos era tão intensa na Idade Média que "quase toda a vida secular" (HEYWOOD, 2002, p.24) ficou ausente de suas obras, não apenas a criança.

A partir da questão “o que é infância?”, diferentes disciplinas formularam várias respostas criando concepções de infância tão díspares quanto curiosas. A professora Marisa Lajolo trata desse tema em um interessante texto "Infância de papel e tinta" 3, do qual tirei alguns exemplos para este artigo. Ela diz que passamos por diferentes concepções de infância...

...primeiro vendo a criança como um adulto em miniatura; depois concebendo-a como um ser essencialmente diferente do adulto, depois...Fomos

3 In FREITAS, História social da infância no Brasil. Cortez, 1997, p.225-245. 
acreditando sucessivamente que a criança é uma tábula rasa, onde se pode inscrever qualquer coisa, ou que seu modo de ser adulto é predeterminado pela sua carga genética, ou ainda que as crianças do sexo feminino já nascem carentes de pênis....

(LAJOLO, 1997, p.228)

Nessa citação de Marisa Lajolo, observamos desde uma visão medieval até as teorias de Freud. É importante ressaltar que a literatura acompanha tais mudanças, retratando essas diferentes visões.

Para estabelecer um contraste, partindo para outras artes, podemos observar como a infância é retratada em algumas pinturas.

Na Idade Média, por exemplo, a criança era raramente retratada e , quando isso ocorria, era na figura do menino Jesus. Na pintura de Giotto (fig. 1), por exemplo, Jesus, no colo de Maria, parece mais um adulto em miniatura, o que ratifica a visão teocêntrica do mundo medieval, para a qual retratar a humanidade não era essencial. Já na pintura de Leonardo Da Vinci (fig.2), na Idade Moderna, temos uma visão antropocêntrica e uma nova forma de representação do menino Jesus, mais humana.

Figura 1

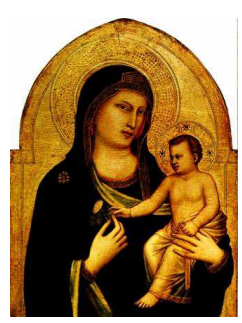

Madona e o Menino

Giotto di Bondone

(1267-1337)

www.klickeducacao.com.br
Figura 2

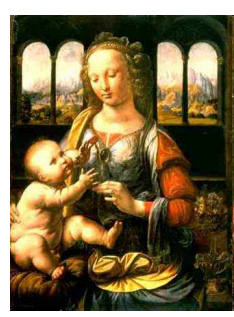

Madona do Cravo

Leonardo Da Vinci

(1452-1519)

Fonte:

www.portalsaofrancisco.com.br

Pensando nos temas abordados por Collin Heywood, citamos algumas considerações sobre a inocência da criança. 
Para Santo Agostinho (354-430), por exemplo, a criança era vista como uma criatura com vontade própria, igual a um adulto, ou seja, maculada pelo pecado original.

Vale dizer que essa visão foi predominante até o século XII. Anos após, observamos que Lutero mantém a postura de que adultos e crianças são detentores do pecado original. Contudo, ele se contradiz ao se referir às crianças de até os 6 anos como "os pequenos ingênuos de Deus" (OSMENT, 1983, p.164 apud HEYWOOD, 2002, p.50).

No século XVIII, Jacques Rousseau se opõe à tradição cristã do pecado original e considera a criança como um ser inocente por natureza. Há, entretanto, nessa mesma época, posturas divergentes. Heywood cita uma religiosa inglesa, Sra. Sherwood, que considerava a criança má por natureza, havendo assim a necessidade de que os pais fossem devotos e prudentes para guiá-la.

Outro tema abordado por Heywwod é a questão do caráter e da inteligência das crianças.

Na Idade Média, o caráter e a inteligência eram tidos como inatos ao ser humano. Um nobre, por exemplo, que fosse criado por camponeses, nunca perderia sua essência de gentleman, enquanto a um pobre lavrador nunca poderiam ser ensinadas boas maneiras.

John Locke, em seu influente livro Concerning education (1693), traz uma nova visão sobre a criança, considerando-a um ser fraco que precisava de ajuda, uma tábula rasa, uma folha em branco. Do século XX até hoje, há um equilíbrio entre o inato e o adquirido.

No Iluminismo, a criança passou a ser vista não somente como um ser inocente, mas também como um ser ignorante, que deveria ser civilizado e educado: "Há dois aspectos do sentimento da infância do século XVIII, a inocência que é preciso conservar e a ignorância ou a fraqueza que é preciso suprir ou tornar razoáveis" (ARIÈS, 1981, p.149).

No Romantismo, tem-se uma visão idealizada e sacralizada da criança, que é vista como um ser redentor que proporciona a harmonia. Tomemos como exemplo a pequena Cosette de Os miseráveis, de Victor Hugo, e sua importância na redenção de Jean Valjean. 
Com a Revolução Industrial, a criança pobre passou a viver como na Idade Média, precocemente como um adulto. Houve uma grande diferença de tratamento da criança do povo e da criança burguesa, aguçando-se as diferenças de classes.

Segundo Viviana A. Zelizer, no século XX a "criança é economicamente sem valor, mas emocionalmente inestimável" (ZELIZER, 1985, p 3-6 apud HEYWOOD, 2002, p. 24).

Houve no início do século XX muitas disputas políticas e econômicas que influenciaram conflitos como a Primeira Guerra Mundial, por exemplo. Ao seu término, houve um aumento da falta de empregos, tornando-se necessário que os homens adultos assumissem os postos de trabalho até então ocupados por mulheres e crianças, e estas últimas perderam seu valor econômico.

Como reflexo de tal contexto, surge a busca pela eficiência nacional e contra a degeneração das crianças e jovens, e uma consequente valorização da saúde, educação e moral. Temos, por exemplo, a implantação do escotismo por Baden Powell, com o intuito de proteger os meninos ingleses da degeneração e contato com gangues. É uma posição bastante nacionalista e de preservação. Em um jornal britânico de 1910, temos a seguinte citação: "A criança de hoje tem a chave para o reino de amanhã" (Child Welfare Annual, p.23 apud HEYWOOD, 2002, p.44 ). Há atualmente uma frase similar que já faz parte de nosso senso comum: "as crianças são o futuro da nação."

Vale citar Ariès, quanto ao fato do confinamento da infância:

Passou-se a admitir que a criança não estava madura para a vida, e que era preciso submetê-la a um regime especial, a uma espécie de quarentena antes de deixá-la unir-se aos adultos (....). A família e a escola retiraram juntas a criança da sociedade dos adultos. A escola confinou uma infância livre num regime disciplinar cada vez mais rigoroso, que nos séculos XVIII e XIX resultou no enclausuramento total do internato. (ARIĖS, p.277) 
Note-se que crianças e adultos viviam em um mesmo universo e pouco se diferenciavam, até que se "descobre" a infância e passa-se a encará-la de forma diferente.

Como exemplo, podemos citar uma pintura de Joshua Reynolds (fig.3) que ilustra a nova concepção de criança inocente e frágil, até hoje considerada. Com o sugestivo nome de "idade da inocência", essa pintura apresenta uma menininha de ar inocente e frágil, branca e possivelmente burguesa.

Figura 3

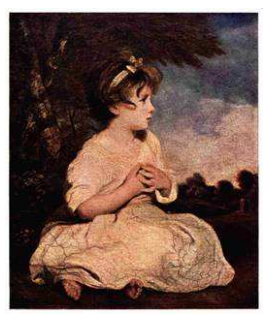

Age of innocence- 1788

Joshua Reynolds

www.gutenberg.org/.../29532h/images/plate40.jpg

Para uma construção de infância, ou diversas concepções, os autores têm se baseado em biografias, autobiografias, diários, documentos oficiais, manuais de conduta, iconografia, brinquedos, textos literários para adultos, para crianças, tanto em livros como em jornais e revistas. E é neste ponto que falaremos especificamente da literatura. Segundo Marisa Lajolo:

Enquanto formadora de imagens, a literatura mergulha no imaginário coletivo e simultaneamente o fecunda, construindo e desconstruindo perfis de crianças que parecem combinar bem com as imagens de infância formuladas e postas em circulação a partir de outras esferas, sejam estas científicas, politicas, econômicas ou artísticas.(1997, p.228)

Como vemos, a contribuição da literatura é extremamente rica para as diferentes concepções de infância. 
Em seu texto, Lajolo cita um fragmento do poema "Meus oito anos" de Casimiro de Abreu, representante do Romantismo no Brasil. Vejamos:

Como são belos os dias

Do despontar da existência!

-Respira a alma inocência

Como perfumes a flor;

O mar é - lago sereno,

O céu - um manto azulado,

O mundo - um sonho dourado,

A vida - um hino d'amor!

(...)

Oh! dias da minha infância!

Oh! meu céu de primavera!

Que doce a vida não era

Nessa risonha manhã!

(ABREU, apud CANDIDO, 1981, p.41)4

Podemos observar a visão romântica e idealizada da infância, período em que a própria natureza colabora com a existência, sendo o mundo um sonho dourado e a manhã risonha. Ou seja, o melhor momento da vida.

Em outro texto escolhido por nós, um fragmento de Memórias póstumas de Brás Cubas (1881) de Machado de Assis, observamos que a inocência e a pureza da criança são colocadas em xeque:

Desde os cinco anos merecera eu a alcunha de 'menino diabo'; e verdadeiramente não era outra coisa; fui dos mais malignos do meu tempo, arguto, indiscreto, traquinas e voluntarioso. Por exemplo, um dia quebrei a cabeça de uma escrava, porque me negara uma colher do doce de coco que estava fazendo, e, não contente com o malefício, deitei um punhado de cinza ao tacho, e, não satisfeito da travessura, fui dizer à minha mãe que a

\footnotetext{
${ }_{4}^{4}$ Publicado originalmente no livro As primaveras de 1859.
} 
escrava é que estragara o doce 'por pirraça'; e eu tinha apenas seis anos. (ASSIS, 2004, p.32)

Já dentro da estética realista, nota-se que o narrador-personagem se autointitula como um "menino diabo", ou seja, a inocência para essa criança de seis anos não existia. Ao ler todo o capítulo, ainda verificamos que o menino era mimado e não respeitava ninguém. $O$ título do capítulo, "O menino é o pai do homem", é uma frase do poeta inglês Wordsworth, considerando que o caráter do adulto já estaria determinado na infância.

O próximo texto também foi citado por Marisa Lajolo e pertence ao Pré-modernismo:

Negrinha era uma pobre órfã de sete anos. Preta? Não; fusca, mulatinha escura, de cabelos ruços e olhos assustados.

Nascera na senzala, de mãe escrava, e seus primeiros anos vivera-os pelos cantos escuros da cozinha, sobre velha esteira e trapos imundos.

Sempre escondida, que a patroa não gostava de crianças. (...)

Que idéia faria de si essa criança que nunca ouvira uma palavra de carinho? Pestinha, diabo, coruja, barata descascada, bruxa, pata choca, pinto gorado, moscamorta, sujeira, bisca, trapo, cachorrinha, coisa-ruim, lixo - não tinha conta o número de apelidos com que a mimoseavam. (LOBATO, 2008, p.19)

Esse conto de Lobato, publicado originalmente em 1923, quando ainda se dedicava à literatura para adultos, é um retrato cruel de uma infância sofrida, de extremo abandono. Há um contraste com a imagem idealizada dos românticos, e mesmo com o burguês, branco e "bem nascido" representado pela personagem Brás Cubas. Mesmo com tanto sofrimento, Negrinha (observe-se a coisificação da personagem, sem um nome próprio) fugia para o mundo da imaginação ao admirar um relógio cuco que ficava na sala, sua única distração.

Já para as crianças, Lobato opta por outra representação da infância, mais adequada a esse público, ou o ideal que fazia deste: 
...Dona Benta é a mais feliz das vovós, porque vive em companhia da mais encantadora das netas - Lúcia, a menina do Narizinho arrebitado, ou Narizinho como todos dizem. Narizinho tem sete anos, é morena como jambo, gosta muito de pipoca e já sabe fazer uns bolinhos de polvilho bem gostosos. (LOBATO, 1972, p.9)

Vale ressaltar que Reinações de Narizinho foi publicado em 1932, a partir da obra, A menina do narizinho arrebitado de 1922, mesma época do conto "Negrinha."

Além da prendada neta de Dona Benta, podemos citar Pedrinho, um menino esperto, bom, corajoso e sempre a procura de aventuras. Crianças cheias de imaginação, cercadas de carinho, protagonistas de suas histórias.

A seguir, temos um trecho de um poema de Manuel Bandeira, "Meninos carvoeiros", publicado em 1921 no livro Ritmo dissoluto:

...Eh, carvoero!

Só mesmo estas crianças raquíticas

Vão bem com estes burrinhos descadeirados.

A madrugada ingênua parece feita para eles...

Pequenina, ingênua miséria!

Adoráveis carvoeirinhos que trabalhais como se brincásseis!

-Eh, carvoero!

Quando voltam, vêm mordendo num pão encarvoado,

Encarapitados nas alimárias,

Apostando corrida,

Dançando, bamboleando nas cangalhas como espantalhos desamparados. (BANDEIRA, 2007, p.47)

Nesse trecho, podemos destacar a analogia entre as crianças raquíticas e os burrinhos descadeirados, uma vez que as crianças passam por um processo de zoomorfização, tão semelhantes aos animais. Uma infância em que trabalho e brincadeira se fundem 
paradoxalmente. A madrugada é ingênua, a miséria é ingênua. E a criança?

Tais diferentes concepções de infância também podem ser observadas nos jornais para crianças que fazem parte do corpus de nossa tese.

Primeiramente, citaremos o jornal português $O$ Senhor Doutor (fig. 4) de 1933, que circulava aos sábados, apresentando poemas, contos, HQ (bandas desenhadas), charadas, piadas, textos didáticos de história, ciências, alguns instrucionais, específicos para meninas ("como fazer um babador"). Nesse período temos o início do Salazarismo, ditadura portuguesa que durou até 1974. Os jornais eram revisados pela censura e apresentavam, de forma generalizada, textos didatizantes, moralistas e nacionalistas.

Vejamos o editorial da primeira edição que, apesar de não ser um texto literário, nos elucida o público leitor desejado:

Aqui têm o primeiro número dum jornal que foi feito de propósito para vocês, atendendo às vossas predilecções, aos vossos gostos, gostos que têm a vantagem de serem uniforme, sem as diferenças que distinguem as das pessoas crescidas (...) Todos gostam de histórias movimentadas, de bonecos coloridos, de jogos, de selos, de berlindes, de fitas de animatógrafo. Não é verdade?

Pois o SENHOR DOUTOR, que é um burro velho, sabe isso muito bem, e está disposto a fornecer-lhes todos os sábados, copiosamente a lenha de que vocês precisam para atear o fôgo sagrado da mocidade bem-disposta que é o melhor que se leva desse mundo. ${ }^{5}$ ( $O$ Senhor Doutor, 18/03/ 1933, p. 1)

Como se vê, a infância, de forma idealizada, é vista como a melhor fase da vida. Além disso, a criança, um ser frágil e ignorante, deveria ser protegida e conduzida, inclusive em suas preferências. Além do que, não são vistos em sua individualidade e sim como um corpo uniforme.

\footnotetext{
5 Para os textos retirados do jornal $O$ Senhor Doutor e a revista $O$ Tico-Tico, mantivemos a ortografia original.
} 
Vejamos um trecho de um conto intitulado "Que feio ser invejoso":

- Sérgio, se continuas, castigo-te! - exclamava, severa a mãe deste menino de dez anos. Ordenara a boa senhora ao seu filho, que entretivesse Ligita - a irmãzinha mais nova, enquanto ela e as criadas procediam a certos arranjos de casa. Sérgio, em vez de brincar com a pequenina - fresco botãozinho de rosa que, há pouco fizera um ano - arrelia-a, fá-la chorar! A mãe deu a Ligita um bolo, igual a outro com que mimoseára Sérgio, que rapidamente comera o seu e queria mais. Como lho negasse, cheio de inveja, aflige a irmã que faz beicinho e implora socorro materno...(COSTA, Emilia de Sousa, "Que feio ser invejoso", O Senhor Doutor, 18/03/1933, p. 6 e 11$)$

Em suas atitudes maldosas, Sérgio assemelha-se ao pequeno Brás Cubas, enquanto sua irmãzinha é um anjo desprotegido. Nessa história, o menino mantém seu comportamento invejoso na escola e cobiça uma carta que um amigo sempre leva consigo. Quando descobre que a carta era da mãe falecida de seu colega, teme pela morte de sua mãe, se arrepende e se torna uma pessoa melhor. Mais uma vez, a criança precisa ser educada, conduzida para os principios morais.

Figura 4

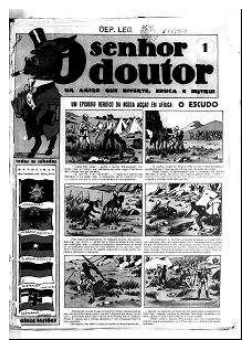

Jornal O Senhor Doutor -

$18 / 03 / 1933$
Figura 5

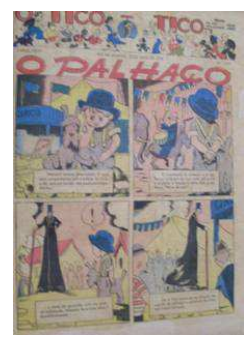

Revista O Tico-Tico -

$25 / 05 / 1938$ 
Outro objeto de nossa pesquisa é a revista $O$ Tico-Tico (fig. 5). Como o jornal O Senhor Doutor, essa revista apresenta diferentes gêneros, com histórias traduzidas e HQ decalcadas, como do Mickey, Beth Boopy, Tex, entre outros. As HQ, em suas origens, assemelham-se aos livros infantis, com ilustrações e legendas abaixo delas, sem o uso de balões.

Há ainda muitos textos sem assinatura ou com pseudônimos, dificultando a identificação do autor, que é o caso do conto a seguir, "O pequeno das sortes":

Último bilhete! Quem compra?... Olha a sorte grande! Assim apregoava Antonico, alegremente, porque um senhor bondoso lhe dera uma boa gorjeta de cinco mil réis. Todo contente, passava assim apregoando pela avenida Rio Branco, a mais bela artéria da capital do Brasil. Antonico, apesar de sua pouca idade, já tinha uma larga compreensão da vida.

Quase sempre tinha sorte (...). Mas um dia teve azar... não conseguira vender nenhum único bilhete..nem ao menos uma gorjetinha. Antonico, de tal modo se entristeceu, que seus lindos olhos se marejavam de lágrimas ao lembrar que sua mãezinha estava gravemente enferma, que, de tanto coser, adoecera repentinamente...(SZEWSKA , Olga Jan. "O pequeno das sortes" in O Tico-Tico, 25/05/1938, p.23)

Observamos que Antonico é um menino pobre, trabalhador, de bom coração. Provavelmente, os semelhantes a ele não teriam acesso a essa revista, mas o menino seria um modelo de comportamento para os "bem nascidos". Mesmo sem dinheiro, Antonico dá um bilhete a um pobre mendigo que fica rico e o ajuda, ou seja, ele foi recompensado por sua boa ação.

Haveria ainda muitos outros exemplos a serem analisados, contudo nos ativemos somente a alguns que se mostraram significativos dentro de uma variedade de concepções.

Em nossas considerações finais, podemos afirmar que conhecer e refletir sobre as diferentes concepções de infância ao longo dos tempos é fundamental para uma compreensão mais ampla e consistente do processo de formação da literatura infantil e juvenil em Língua 
Portuguesa, assim como para sua contemporaneidade e perspectivas futuras.

\section{Referências bibliográficas}

ABREU, Casimiro de. "Meus oito anos" in CANDIDO \& CASTELLO, Antônio e J. Aderaldo. Presença da literatura brasileira. 9. ed.São Paulo: Difel, 1981.

ARIÉS, Philippe. História social da criança e da família. trad. Dora Flaksman. 2.ed. Rio de Janeiro: LTC Livros Técnicos e Científicos, 1981.

ASSIS, Machado de. Memórias póstumas de Brás Cubas. 28. ed. São Paulo: Ática, 2008.

BANDEIRA, Manuel. "Meninos carvoeiros" in Meus poemas preferidos. Rio de Janeiro: Ediouro, 2007.

HEYWOOD, Colin. Uma história da infância. Da Idade Média à Época contemporânea no ocidente. Trad. Roberto Cataldo Costa. São Paulo: Artmed, 2004.

LAJOLO, Marisa. "Infância de papel e tinta" in FREITAS, Marcos César. org. História social da infância no Brasil. São Paulo: Cortez, 1997.

LOBATO, Monteiro. Negrinha. São Paulo: Globo, 2008.

Reinações de Narizinho. 25. ed.São Paulo: Brasiliense, 1972. 


\section{Periódicos.}

O Senhor Doutor,18/03/1933- digitalizado a partir de microfilme cedido pela Biblioteca Nacional de Portugal.

O Tico-Tico, 25/05/1938- fotografias tiradas em 2008. O exemplar faz parte do acervo da Biblioteca Monteiro Lobato em São Paulo, capital. 